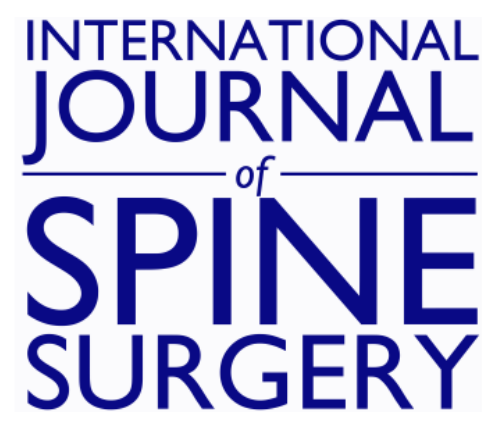

\title{
Evaluation of Perivascular Adhesion Formation in New Zealand White Rabbits Using Oxiplex and DuraSeal Xact Adhesion Barrier System
}

Fred Mo, James Yue, Jianghui Zhang, Kreg Howk and Allister Williams

Int J Spine Surg 2009, 3 (2) 68-76

doi: https://doi.org/10.1016/SASJ-2009-0006-NT

http://ijssurgery.com/content/3/2/68

This information is current as of April 26, 2023.

Email Alerts Receive free email-alerts when new articles cite this article. Sign up at:

http://ijssurgery.com/alerts

The International Journal of Spine Surgery

2397 Waterbury Circle, Suite 1,

Aurora, IL 60504, Phone: +1-630-375-1432 


\title{
Evaluation of Perivascular Adhesion Formation in New Zealand White Rabbits Using Oxiplex and DuraSeal Xact Adhesion Barrier System
}

\author{
Fred Mo, MD, ${ }^{a}$ James Yue, MD, ${ }^{a}$ Jianghui Zhang, MD, ${ }^{a}$ Kreg Howk, MS, ${ }^{b}$ and Allister Williams, MD ${ }^{a}$
}

\begin{abstract}
Background

Adhesion formation after spine surgery is a result of normal wound healing that may place patients at increased risk for complications during revision surgery. Preventing adhesions could reduce the risk of complications during revision surgery, and possibly reduce the need for revision procedures. This study evaluates the ability of DuraSeal Xact Adhesion Barrier System (DSX) (Covidien, Mansfield, Massachusetts) and Oxiplex/SP gel (OX) (FzioMed, San Luis Obispo, California) to affect the extent and severity of postoperative perivascular adhesion development in an anterior spinal surgical rabbit model.
\end{abstract}

Methods

We determined the extent and severity of postoperative adhesion development 34 days after surgery in 12 male New Zealand White rabbits randomly assigned to intraoperative treatment with either DSX or OX, or to an untreated control group. Adhesion severity and extent were scored on scale from 0 (none) to 3 (severe).

Results

The extent and severity of adhesions in the DSX group were significantly less than in the untreated control group. The DSX group mean extent score was $1.3 \pm 0.5$ (vs $2.5, \mathrm{P}=.01$ ) and the mean severity score was $1.25 \pm 0.5$ (vs $2.8, \mathrm{P}=.005)$. The extent and severity of adhesions in the OX group were not significantly different from the control group.

\section{Conclusion}

In this study, we found DSX to be the most effective compound in preventing adhesion formation after anterior spine surgery.

\section{Clinical Relevance}

Extrapolating these results in rabbits to humans, less scarring between the major blood vessels could decrease the rate of complications in revision spine procedures.

Key Words: Perivascular adhesions; DuraSeal Xact; PEG hydrogel; Oxiplex; surgical sealant; adhesion barrier. SAS Journal. June 2009;3:68-76. DOI: SASJ-2009-0006-NT

a'Department of Orthopaedics and Rehabilitation, Yale University School of Medicine, ${ }^{\mathrm{b} C o v i d i e n}$

Address correspondence to Dr. James Yue, Department of Orthopaedics and Rehabilitation, Yale University School of Medicine, 800 Howard Ave, New Haven, CT 06511 (e-mail: james.yue@yale.edu)

\section{INTRODUCTION}

Normal healing involves migration of fibroblasts to a wound site to form a matrix of scar tissue, but unwanted scar tissue between normally opposed but separate tissue, generally known as an adhesion, is a potential consequence of any surgical procedure. ${ }^{1}$ Adhesions hold particular importance for spinal and cranial procedures because the progressive formation and contraction of scar tissue around surgically exposed dura mater and nerve roots has long been implicated as one of the major causes of recurrent radicular and low-back pain after an otherwise successful laminectomy or discectomy.
Each year, approximately 800,000 patients worldwide undergo lumbar surgeries, of whom $5 \%$ to $40 \%$ experience recurrent back pain along with limited activity and mobility. ${ }^{2,3}$ Approximately $15 \%$ of patients require reoperation within 5 years of initial surgery. ${ }^{4-6}$ Fibrosis is recognized as one of the most frequent etiopathologic factors that contributes to initial surgical failure and prompts revision surgery. ${ }^{7}$ Revision surgery frequently reveals dense scar tissue at the initial surgical site and makes the isolation of spinal anatomy extremely challenging and time-consuming, which may increase the potential for accidental durotomy or other complications. 
Many surgical products have been developed and evaluated for their ability to minimize scarring, often with inconsistent results. ${ }^{8-22}$ One of these antiadhesion formulations is the DuraSeal Xact Adhesion Barrier and Sealant System (DSX) (Covidien, Waltham, Massachusetts), a synthetic and resorbable hydrogel that polymerizes in seconds in situ. DSX was developed for use in neurosurgical procedures as a dural sealant, to provide watertight closure, and as an adhesion barrier for the inhibition of postsurgical peridural fibrosis. Another antiadhesion compound is Oxiplex/SP Gel (OX) (FzioMed, San Luis Obispo, California), a combination of carboxymethylcellulose and polyethylene oxide that is used to coat exposed surgical sites to prevent scarring. International experience with OX has been reported for gynecologic and spinal surgery, but it is currently not approved for use in the United States. ${ }^{23-28}$

This study was undertaken to specifically evaluate how these products affect adhesion formation around blood vessels near the spine, because normal wound healing after spine surgery results in adhesions and fibrosis that may entrap blood vessels and nerves. As a result of adhesion formation, revision spine surgery has inherently greater risk than primary surgery, especially due to the adhesions that form around the great vessels. ${ }^{29}$ _The risk remains high even when the revision is performed through a different surgical approach. ${ }^{30}$ If the extent and severity of adhesions to blood vessels can be reduced, there may be a decreased need for revision surgery, and should revision surgery be required, the risks inherent to adhesion removal would be diminished.

\section{MATERIALS AND METHODS \\ Study Design}

The extent and severity of postoperative adhesion development 34 days after surgery was determined in 12 male New Zealand White rabbits that were randomly assigned to intraoperative treatment with either DSX or $\mathrm{OX}$, or to an untreated control group.

All animals were cared for in accordance with the Yale University Institutional Animal Care and Use Committee protocols.

\section{Study Material}

DSX (lot number C050976) was provided by the manufacturer and prepared and applied according to instructions for use. OX (lot number 15071) was obtained from a European distributor and applied according to instructions on the package insert.

\section{Surgical Procedure}

Anesthesia was induced by intramuscular administration of ketamine $(35 \mathrm{mg} / \mathrm{kg})$ and xylazine $(2.5 \mathrm{mg} / \mathrm{kg})$; anesthesia was maintained by inhaled isoflurane $(0.5 \%$ to $3.5 \%)$ with oxygen. Analgesia was provided by a fentanyl patch $(25 \mathrm{mcg})$ and supplemented with buprenorphine $(0.01$ to $0.05 \mathrm{mg} / \mathrm{kg}$ [IM or $\mathrm{SC}]$ ), if needed. Antibiotic coverage was provided by enrofloxacin (5 to $10 \mathrm{mg} / \mathrm{kg}$ ), administered preoperatively and postoperatively for 5 days.

The rabbits were shaved, positioned in right lateral recumbency, scrubbed with betadine and alcohol, and prepped in a standard surgical fashion. A longitudinal skin incision was made in the lumbar region from the inferior margin of the rib cage to the pelvic brim, 2 $\mathrm{cm}$ ventral to paraspinal musculature. Using blunt and sharp dissection of the overlying subcutaneous tissue, retroperitoneal fat, and musculature, the left anterolateral vertebral column from L1 to L6 was exposed. The surgical levels were identified by referencing the pelvic brim with manual palpation. At the level of the aortic bifurcation, the inferior vena cava and abdominal aorta were separated from each other and from the psoas muscles by blunt dissection (Figure 1). No additional abrasive or traumatic procedures were performed on the exposed vessels and tissues.

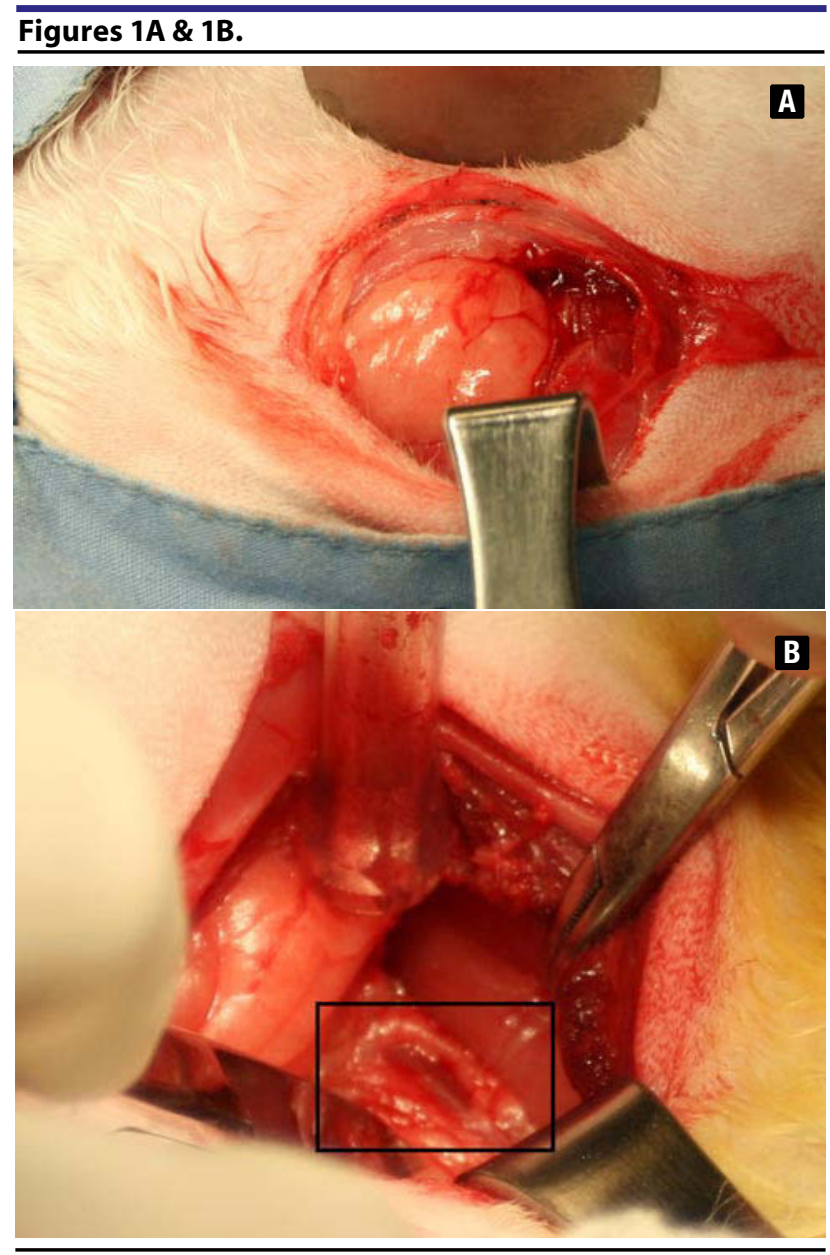

Dissection through skin and subcutaneous tissue. Identification of major vessels is indicated by the black rectangle. 


\section{SASJournal}

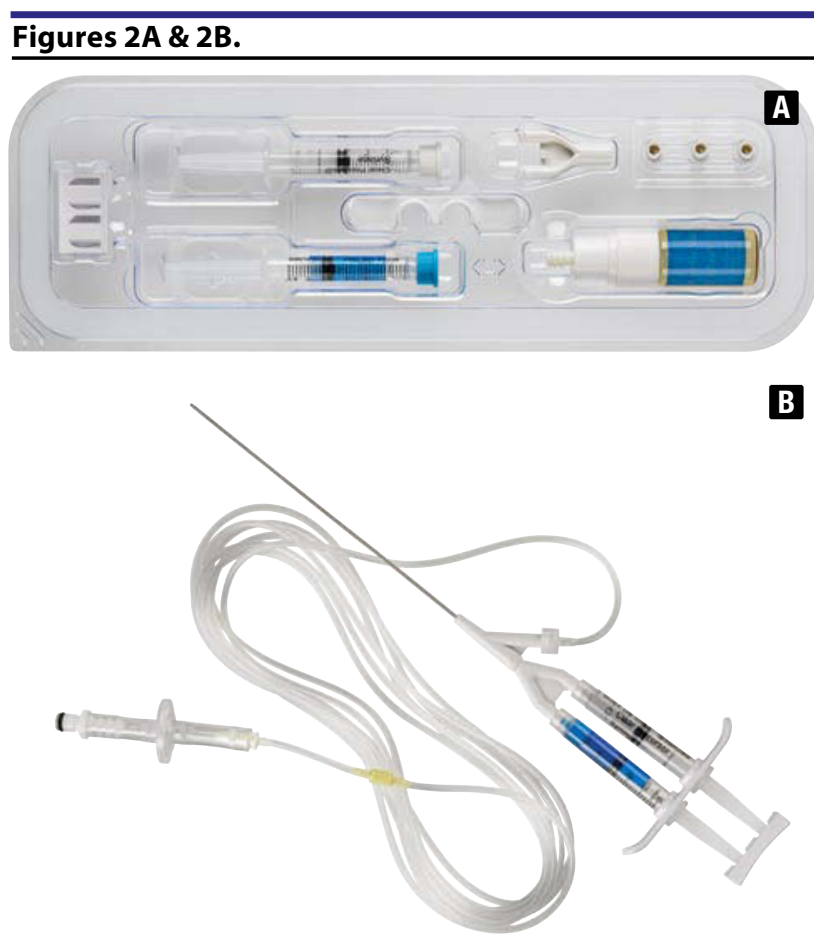

Figures $2 \mathrm{~A}$ and $2 \mathrm{~B}$. (A) DSX is supplied as a kit with blue and clear precursor solutions and a mixing device. (B) It is prepared and applied simultaneously using the applicator.

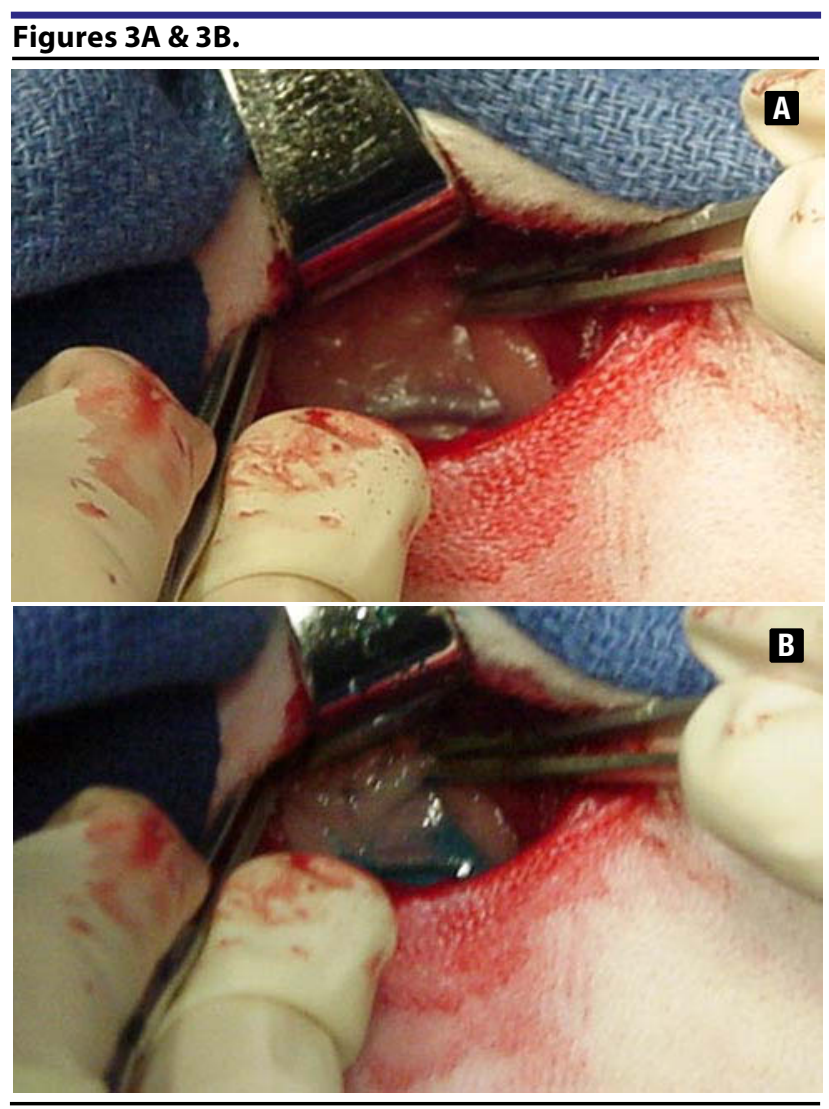

DSX in situ. (A) Vessel before DSX application. (B) Vessel after DSX application. The application site is precisely identified by the blue color.

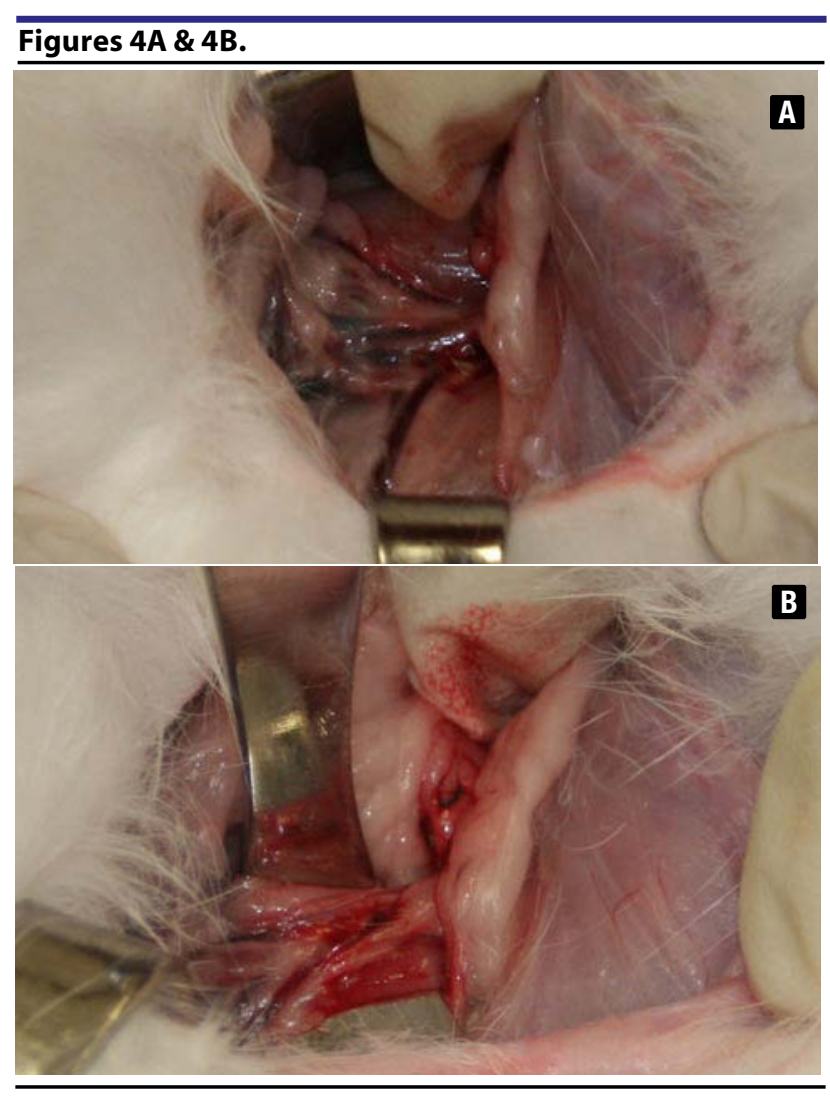

Necropsy images. (A) In the untreated control group, major vessels were surrounded by adhesions. (B) In the DSX group, adhesions in the treatment area were minimal, enabling easy mobilization and identification of anatomic structures.

After dissection was complete and the vessels isolated, the rabbits were randomized into treatment groups (4 per group) and the vessels were treated according to the manufacturers' recommendations for each product. For DSX, the blue and clear precursors were prepared and applied simultaneously using the MicroMyst applicator (Figures 2A and 2B, Figures $3 \mathrm{~A}$ and 3B). OX was provided in a kit consisting of a syringe and a single applicator. The applicator was connected to the syringe and the gel was applied to the surgical site using a drip technique.

After applying the materials, the posterior peritoneum, abdominal wall, and skin were closed with polyglactin 910 suture material, and the incision site was covered with sterile dressing. The rabbits had their skin sutures removed on day 14 and were monitored for a total of 34 to 35 postoperative days. After the monitoring period, all animals were euthanized via intracardiac pentobarbital overdose. The site of surgery/treatment was re-accessed, and the extent and severity of adhesions were measured by an investigator blinded to the treatment group.

\section{Adhesion Assessment}

The extent of adhesions was graded on a 0 to 3 scale, as follows: (0) no adhesions, (1) adhesions on $<25 \%$ 
of the area, (2) adhesions on $25 \%$ to $50 \%$ of the area, (3) adhesions on $>50 \%$ of the area. The severity of adhesions was also graded on a 0 to 3 scale, as follows: (0) no adhesions, (1) slight resistance required to separate tissue, (2) moderate resistance with blunt dissection required to separate tissue, (3) high resistance with sharp dissection required to separate tissue.

\section{Statistical Methods}

The extent and severity of adhesions were compared using the Student's t test for 2 samples assuming unequal variances.

\section{RESULTS}

All groups exhibited a normal degree of wound healing, normal tissue integrity, and no presence of infection or necrosis. Residual treatment material was not found in any operative site.

\section{Untreated Controls}

The extent and severity of adhesions were greater in the untreated control group than in either the OX or DSX groups. Adhesions occurred between the peritoneum and the great vessels, as well as between the vessels and muscle. The mean adhesion extent score was $2.5 \pm 0.5$ and the mean adhesion severity score was $2.8 \pm 0.58$. In nearly all sites sharp dissection was required to free the vessels from the adhesions (Figures 4A, 5, and 6).

\section{DSX Group}

The extent and severity of adhesions in the DSX group were significantly less than in the untreated control group. The mean extent score was $1.3 \pm 0.5$ (vs $2.5, P$ $=.01$ ) and the mean severity score was $1.25 \pm 0.5$ (vs $2.8, P=.005$ ). The DSX group had the smallest and least severe adhesions. In 3 of the animals, exploration of the old surgical site revealed tissue that appeared substantially untouched by prior surgery. Only slight

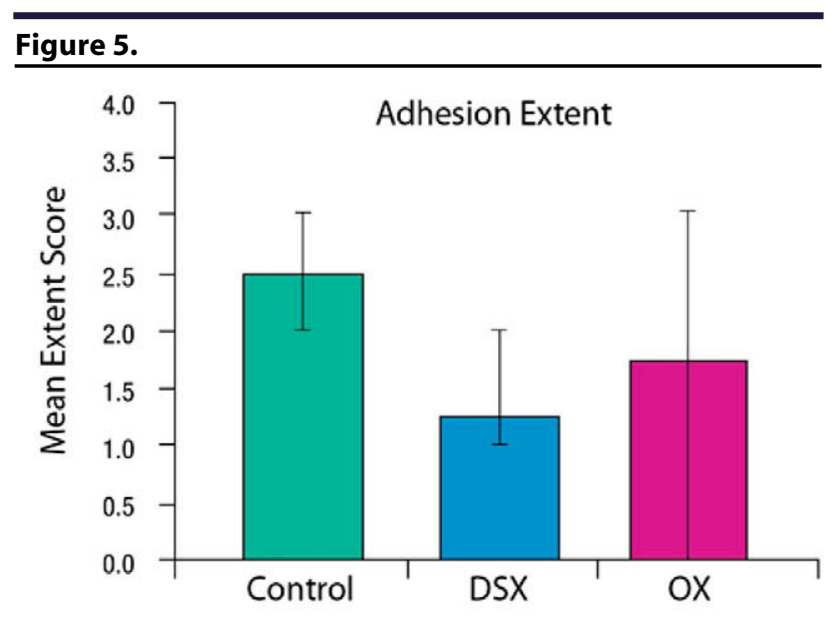

The extent of adhesion in the DSX group was significantly less than in the control group (mean of 1.3 vs $2.5, P \leq .05$ ). The scores for OX were not significantly different from controls and varied widely. resistance was required to identify and maneuver around the great vessels (Figures 4B, 5, and 6).

\section{Figure 6.}

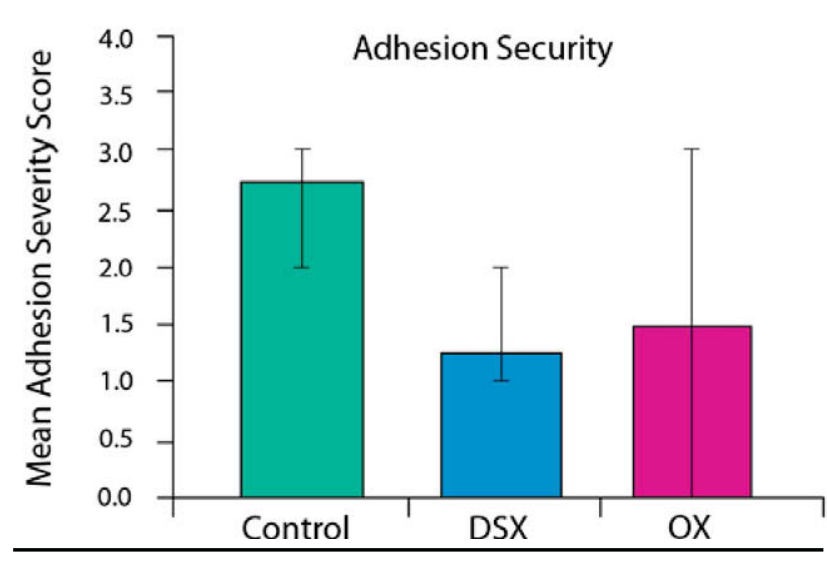

The severity of adhesions in the DSX group was significantly less than in the control group (mean of 1.25 vs $2.8, P \leq .05$ ). The scores for OX were not significantly different from controls and varied widely.

\section{OX Group}

Adhesions in the OX group were highly varied in both severity and extent. In 1 animal, adhesion formation was exuberant, encompassing greater than $50 \%$ of the surgical site and requiring sharp dissection to free the great vessels. In the other animals treated with OX, adhesion severity and extent were similar to the control group, and the difference between them was not statistically significant (Figures 5 and 6). The OX group's mean scores for adhesion extent and adhesion severity were $1.8 \pm 1.5$ and $1.5 \pm 1.3$, respectively.

\section{DISCUSSION}

Perivascular adhesions increase the risks associated with revision spine surgery. Compounds with adhesion barrier properties, if used at the time of primary surgery, could decrease the extent and severity of adhesions and theoretically reduce the risk of injury to large vessels or the dura during revision surgery. In this trial we used a model of perivascular adhesion development to compare the ability of 2 compounds, DSX and OX, to reduce the extent and severity of adhesion formation.

Adhesion development in the untreated control group was dramatic in both extent and severity. Because we did not disturb exposed tissue in the surgical site with gauze or other abrasives, the adhesions that formed should be typical of those encountered following surgery in which the use of gauze, sponges, and other potential irritants was minimal.

Application of DSX was associated with a statistically significant reduction in the extent and severity of adhesions relative to untreated controls. Most importantly, the results of DSX were consistent among all animals 
tested. Application of the DSX liquid was simple and could be performed consistently. We observed that no residual blue coloration or DSX material was present at 34 days after surgery.

Application of OX was not associated with decreased adhesion extent or severity relative to untreated controls. Furthermore, within the treatment group there was wide variation in adhesion scores. One animal had the highest scores for both extent and severity while another animal had the lowest. This variation may have resulted from the physical properties of OX; its relative lack of tissue adhesiveness enabled it to flow from the site of application into surrounding tissues, and its absence of color made it difficult to accurately visualize its placement in the wound site. The gel also may have been absorbed by the surrounding tissues at various rates, which could account for the observed discrepancies in adhesion formation.

We conclude that in this study, DSX proved to be the most effective compound in preventing adhesion formation after anterior spine surgery in our rabbit model.

This manuscript was submitted to the SAS Journal March 16, 2009 and accepted May 27, 2009.

\section{REFERENCES}

1. Fransen P. Safety of carboxymethylcellulose/polyethylene oxide for the prevention of adhesions in lumbar disc herniation - consecutive case series review. Ann Surg Innov Res. 2008;2:2.

2. Atlas SJ, Deyo RA, Patrick DL, et al. The Quebec task force classification for spinal disorders and the severity, treatment, and outcomes of sciatica and lumbar spinal stenosis. Spine. 1996;21:2885-2892.

3. Long DM, Filtzer DL, BenDebba M, et al. Clinical features of the failed-back syndrome. J Neurosurg. 1988;69:61-71.

4. Hu RW, Jaglal S, Axcell T, et al. A population-based study of reoperations after back surgery. Spine. 1997;22:2265-2271.

5. Malter AD, McNeney B, Loeser JD, et al. 5-year reoperation rates after different types of lumbar spine surgery. Spine. 1998;23:814 820 .

6. Silvers HR, Lewis PJ, Asch HL, et al. Lumbar diskectomy for recurrent disk herniation. J Spinal Disord. 1994;7:408-419.

7. Porchet F, Lombardi D, dePreux J, et al. Inhibition of epidural fibrosis with ADCON-L: effect on clinical outcome one year following reoperation for recurrent radiculopathy. Neurol Res. 1999;21(suppl 1):S51-S60.

8. Ross JS, Obuchowski N, Modic MT. MR evaluation of epidural fibrosis: proposed grading system with intra- and inter-observer variability. Neurol Res. 1999;21:S23-S26.

9. Gill GG, Sakovich L, Thompson E. Pedicle fat grafts for the prevention of scar formation after laminectomy. An experimental study in dogs. Spine. 1979;4:176-186.
10. Robertson JT, Meric AL, Dohan FC Jr, et al. The reduction of post-laminectomy peridural fibrosis in rabbits by a carbohydrate. $J$ Neurosurg. 1993;79:89-95.

11. Inoue $\mathrm{S}$. The effect of fat tissue autotransplantation on the changes in tissue surrounding the dura mater following laminectomy. Nippon Seikeigeka Zasshi. 1989;63:1389-1400.

12. Keller JT, Dunsker SB, McWhorter JM, et al. The fate of autogenous grafts to the spinal dura. An experimental study. J Neurosurg. 1978;49:412-418.

13. Kitano T, Zerwekh JE, Edwards ML, et al. Viscous carboxymethylcellulose in the prevention of epidural scar formation. Spine. 1991;16:820-823.

14. Kuivila TE, Berry JL, Bell GR, et al. Heparinized materials for control of the formation of the laminectomy membrane in experimental laminectomies in dogs. Clin Orthop. 1998;236:166174.

15. Lee HM, Yang KH, Han DY, et al. An experimental study on prevention of postlaminectomy scar formation. Yonsei Med J. 1990;31:359-366.

16. MacKay MA, Fischgrund JS, Herkowitz HN, et al. The effect of interposition membrane on the outcome of lumbar laminectomy and discectomy. Spine. 1995;20:1793-1796.

17. Mikiawa $\mathrm{Y}$, Hahagami H, Higashi S, et al. An experimental study on prevention of post-laminectomy scar formation by the use of new materials. Spine. 1986;11:843-846.

18. Nussbaum CE, McDonald JV, Baggs RB. Use of Vicryl (polyglactin 910) mesh to limit epidural scar formation after laminectomy. Neurosurgery. 1990;26:649-654.

19. Songer MN, Ghosh L, Spencer DL. Effects of sodium hyaluronate on peridural fibrosis after lumbar laminotomy and discectomy. Spine. 1990;15:550-554.

20. Kuhn J, Hoffman B, Knitelius HO, et al. Bilateral subdural hematoma and lumbar pseudomeningocele due to a chronic leakage of liquor cerebrospinalis after a lumber discectomy with the application of ADCON-L gel. J Neurol Neurosurg Psychiatry. 2005;76:1031-1033

21. Heib LD, Stevens DL. Spontaneous postoperative cerebrospinal fluid leaks following application of anti-adhesion barrier gel: case report and review of the literature. Spine. 2001;26:748-751.

22. Geisler FH. Prevention of peridural fibrosis: current methodologies. Neurol Res. 1999;21:S9-S22.

23. AssiettiR,MoraA,Brayda-BrunoM.Use of carboxymethylcellulose/ polyethylene oxide gel in microdiscectomy with interlaminectomy: a case series comparison with long-term follow-up. Spine. 2008;33:1762-1765.

24. diZerega GS, Coad J, Donnez J. Clinical evaluation of endometriosis and differential response to surgical therapy with and without application of Oxiplex/AP* adhesion barrier gel. Fertil Steril. 2007;87:485-489.

25. Young P, Johns A, Templeman C, et al. Reduction of postoperative adhesions after laparoscopic gynecological surgery with Oxiplex/ AP Gel: a pilot study. Fertil Steril. 2005;84:1450-1456.

26. Rodgers KE, Robertson JT, Espinoza T, et al. Reduction of epidural fibrosis in lumbar surgery with Oxiplex adhesion barriers 
of carboxymethylcellulose and polyethylene oxide. Spine J. 2003;3:277-283.

27. Kim KD, Wang JC, Robertson DP, et al. Reduction of radiculopathy and pain with Oxiplex/SP gel after laminectomy, laminotomy, and discectomy: a pilot clinical study. Spine. 2003;280:1080-1087.

28. Mastronardi L, Pappagallo M, Tatta C. The Oxiplex/SP gelmorphine compound after lumbar microdiscectomy in the management of postoperative pain. Report of 20 cases. Surg Neurol. 2005;64:75-78.

29. Cammisa FP Jr, Girardi FP, Sangani PK, et al: Incidental durotomy in spine surgery. Spine. 2000; 25:2663-2667.

30. Gumbs AA, Hanan S, Yue JJ, Shah RV, Sumpio B. Revision open anterior approaches for spine procedures. Spine J. 2007;7:280-285. Epub January 30, 2007. 


\section{EXTENDED REFERENCES}

Safety of carboxymethylcellulose/polyethylene oxide for the prevention of adhesions in lumbar disc herniation - consecutive case series review.

\section{Fransen $P$}

ABSTRACT: BACKGROUND: Epidural fibrosis is regarded as a cause of failed back surgery syndrome (FBSS) when excessive adhesional/fibrotic scar tissue causes compression, pain or discomfort by tethering of nerve tissue to the surrounding muscle or bone. Fibrosis inhibitors could therefore increase the success rate of spinal surgery and decrease the need for reoperations. In recent years, bio-resorbable gels or films for the prevention of peridural fibrosis and post-operative adhesions have been developed that look clinically promising. This included a $100 \%$ synthetic, sterile, absorbable gel combinations of carboxymethylcellulose (CMC) and polyethylene oxide (PEO) used to coat the dura to reduce scarring after discectomy which became available in Europe in 2002. However, given the burden of the problem and unfavorable experience with other types of adhesion-reduction agents, our unit decided to evaluate the safety of CMC/PEO in a large population of patients undergoing spinal microdiscectomy for herniation. METHODS: To determine the safety and assess efficacy of carboxymethylcellulose/polyethylene oxide (CMC/PEO) gel as an anti-adhesion gel, a consecutive series of 396 patients undergoing lumbar discectomy performed by one surgeon had CMC/PEO gel administered at the end of surgery. The patients were followed up in accordance with standard clinical practice and records reviewed for side effects, such as skin reactions, general reactions or local fluid collections. Reoperations for recurrent herniation included an evaluation of fibrosis reduction. RESULTS: No product related complications were observed. Five patients needed reoperations for recurrent herniation. Significant but subjective reduction in fibrosis was observed in these patients. CONCLUSION: The findings provide confidence that $\mathrm{CMC} / \mathrm{PEO}$ gel is well tolerated as an agent to achieve reduction of fibrosis in lumbar disc surgery. Further formal prospective study is recommended in this area of unmet need.

Inhibition of epidural fibrosis with ADCON-L: effect on clinical outcome one year following re-operation for recurrent lumbar radiculopathy.

\section{Porchet F, Lombardi D, de Preux J, Pople IK.}

In a prospective multicenter study, 20 patients underwent re-operation for recurrent radiculopathy after lumbosacral discectomy, and were treated with ADCON-L (Adhesion Control in a Barrier Gel) to inhibit epidural fibrosis following secondary surgery. Outcomes after re-operation were assessed at six and 12 months using:
Visual Analog Scales to measure radicular and back pain, straight leg raising exams, and self-assessment of activity-related radicular pain. Each parameter was compared to baseline values, obtained immediately prior to the re-operation. The long term clinical results at 12 months after re-operation (summarized below) demonstrate a significant improvement of all clinical parameters, and correlated with the results seen at six months. Radicular pain, measured when most severe, was reduced from an average pre-operative score of 8.1$3.7(P<0.005)$. The straight leg raising angle increased from an average pre-operative value of 41 degrees-67 degrees $(P<0.005)$. Activity-related pain mean score was 4.6 , vs. 17.0 pre-operatively $(P<0.005)$. Low back pain, measured when most severe, was reduced from an average pre-operative score of 6.1 to $3.1(P<0.012)$. These clinical findings compare very favorably with data reported in the literature. There were no adverse events or complications related to the use of ADCON-L.

\section{Viscous carboxymethylcellulose in the prevention of epidural scar formation.}

Kitano T, Zerwekh JE, Edwards ML, Usui Y, Allen MD.

Six chemical agents were evaluated for their efficacy in preventing epidural scar formation following laminectomy in rabbits. One agent was carboxymethylcellulose and the other five agents represented various compositions of modified carboxymethylcellulose. Four weeks after laminectomy, spines were harvested and decalcified, and transverse sections were prepared for histologic analysis. Subjective evaluation suggested that two agents appeared to inhibit epidural scar formation compared with the untreated controls. Objective evaluation was performed by quantitating scar tissue area at the laminectomy site with a digitizing tablet. In agreement with the subjective evaluation, two agents were found to have significantly reduced epidural scar tissue area compared with the control (control $=0.418$ $+/-0.16 \mathrm{SE} \mathrm{mm2vs}$. Agent $2=0.067+/-0.02[P$ less than 0.05] and Agent $5=0.089+/-0.02[P$ less than 0.05]). Of the remaining four agents, one of which was the unmodified carboxymethylcellulose, none showed significant reduction in scar tissue formation. These findings indicate that viscous preparations of modified carboxymethylcellulose can act as a barrier against epidural scar formation following laminectomy.

\section{Effects of sodium hyaluronate on peridural fibrosis} after lumbar laminotomy and discectomy.

Songer MN, Ghosh L, Spencer DL.

Sodium hyaluronate, $1.9 \%$ solution, was evaluated for its ability to retard peridural fibrosis after unilateral lumbar hemilaminotomy, anular fenestration, and nuclectomy in dogs. Three materials: fat grafts, gelfoam, 
and sodium hyaluronate, were compared with empty controls for their ability to inhibit peridural fibrosis. Each dog served as his own internal control and the formation of fibrosis was evaluated at 2, 4, 12, and 26 weeks. Sodium hyaluronate was found to inhibit fibrosis more than the other materials on both a macroscopic and microscopic level. The area of fibrosis and tenacity of the adhesions on dissection were notably less in the sodium hyaluronate group. Microscopically, the thickness of collagen and number of fibroblasts were decreased with the use of $1.9 \%$ sodium hyaluronate. The peridural fibrosis occurred equally both anteriorly and posteriorly to the nerve roots and correlated with the area of surgical dissection. Fat grafts were not effective in preventing fibrosis anteriorly, especially in the region of the exiting nerve roots. Gelfoam did not inhibit but actually appeared to increase fibrosis formation. Interposition materials currently used in humans to prevent scar formation such as gelfoam and fat grafts have only addressed the posterior scar formation, which do little to alter the fibrosis anteriorly. The adhesions between the nerve root and the anulus fibrosus bind the nerve root down anteriorly, making it more vulnerable to recurrent disc herniation. Sodium hyaluronate, $1.9 \%$ solution, with its viscous semifluid properties, coats the nerve roots and dura anteriorly and posteriorly. 


\section{SUPPLEMENTARY DATA}

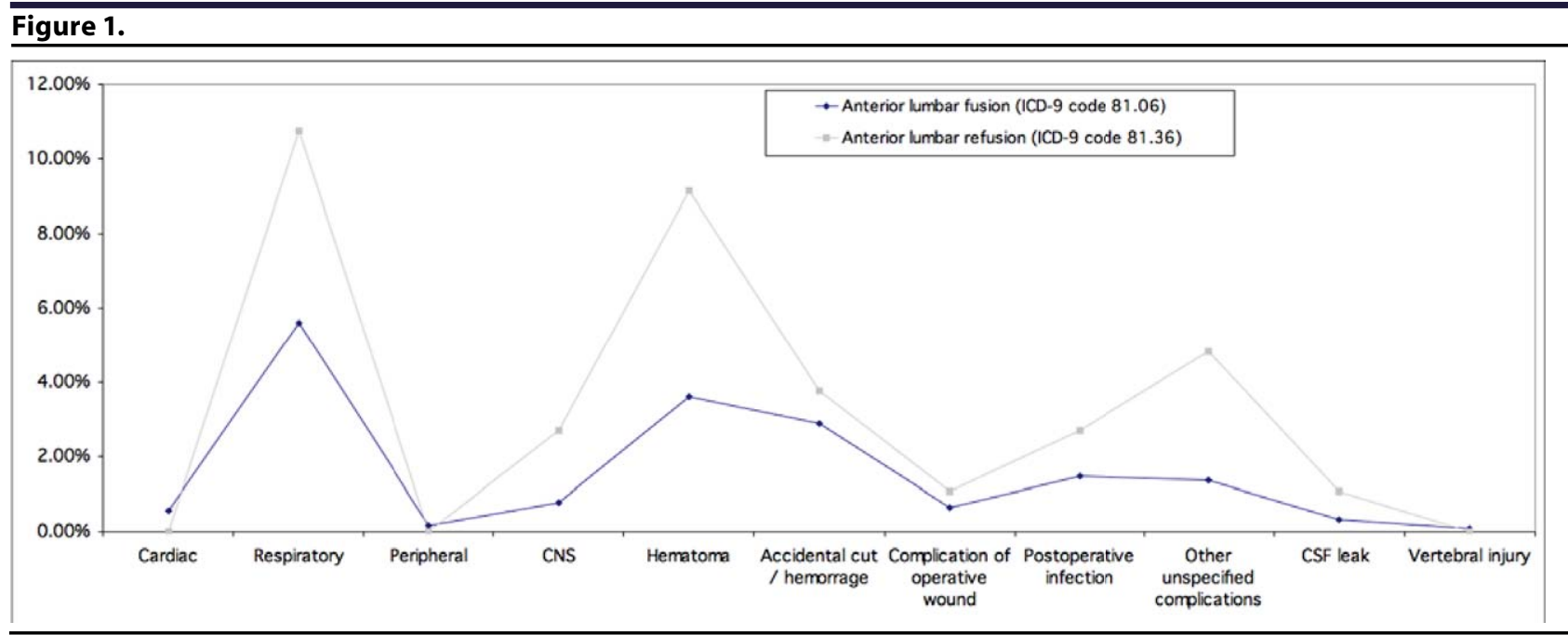

Complications arising from anterior lumbar fusions vs. refusions.

Table 1. Incidence of dural tears in various operations in the MedPar database (Age 65 or over, United States).

\begin{tabular}{lc}
\hline \multicolumn{1}{c}{ Operation } & $\%$ \\
\hline $\begin{array}{l}\text { Refusion of lumbar and lumbosacral spine, posterior } \\
\text { technique }\end{array}$ & $7.3 \%$ \\
Posterior dorsal and dorsolumbar fusion & $6.8 \%$ \\
$\begin{array}{l}\text { Refusion of lumbar and lumbosacral spine, anterior } \\
\text { technique }\end{array}$ & $6.8 \%$ \\
$\begin{array}{l}\text { Refusion of dorsal and dorsolumbar spine, posterior } \\
\text { technique }\end{array}$ & $6.6 \%$ \\
Re-open laminectomy site & $6.0 \%$ \\
Posterior lumbar fusion & $5.8 \%$ \\
Anterior lumbar fusion & $5.7 \%$ \\
Refusion of lumbar spine, lateral transverse process & $5.4 \%$ \\
technique & $5.4 \%$ \\
Anterior dorsal and dorsolumbar fusion & $5.2 \%$ \\
Decompression of the spinal canal & $4.5 \%$ \\
Lateral lumbar fusion & $3.5 \%$ \\
Discectomy & $2.3 \%$ \\
Refusion of other cervical spine, posterior technique & $1.7 \%$ \\
Spine fusion, nos & $1.5 \%$ \\
Atlas-axis spine fusion & $1.4 \%$ \\
Repair of vertebral fracture & $1.3 \%$ \\
Posterior cervical fusion & $1.2 \%$ \\
Refusion of other cervical spine, anterior technique & $0.5 \%$ \\
Anterior cervical fusion & \\
Refusion of dorsal and dorsolumbar spine, anterior & $0.0 \%$ \\
technique & \\
\hline &
\end{tabular}

Source: PearlDiver data derived from HIPAA-compliant insurance and private payer sources. These tables and charts are for information purposes only. The PearlDiver data has been obtained or derived from sources believed by PearlDiver to be reliable, but PearlDiver Technologies Inc. does not represent that the information is $100 \%$ accurate or complete. Any opinions or estimates which form any portion of the tables, charts or other aspects of this report represent the judgment of PearlDiver's analysts and management and are subject to change without notice. Copyright (C) 2009 PearlDiver Technologies Inc. 